\title{
EVALUATION OF IMPACT OF ELEVATED TEMPERATURES ON YOUNG'S MODULUS OF GLT BEAMS
}

\author{
Lucie Kucíkováa, ${ }^{a,}$, Michal Šejnoha $^{a}$, Tomáš Janda ${ }^{a}$, Pavel Padevět ${ }^{a}$, \\ Guido MARSEGLia ${ }^{b, c}$ \\ ${ }^{a}$ Czech Technical University in Prague, Faculty of Civil Engineering, Department of Mechanics, Thákurova 7, \\ 16629 Prague 6, Czech Republic \\ ${ }^{b}$ University of Seville, High Technical School of Architecture, Av. de la Reina Mercedes, 2, 41012 Seville, Spain \\ ${ }^{c}$ University of Seville, Instituto de Matemáticas de la Universidad de Sevilla, (IMUS), Avenida Reina \\ Mercedes 41012 Seville, Spain \\ * corresponding author: lucie.kucikova@fsv.cvut.cz
}

\begin{abstract}
The influence of elevated temperatures on mechanical behavior of glued laminated timber beams is examined on the basis of tensile tests. Dog bone samples prepared from beams exposed to fire of variable duration were categorized with respect to the type and position of the failure crack, type and number of discontinuities such as knots, and the level of browning. The acquired experimental results suggest that the wood variability and the effect of growth discontinuities are probably more significant than the effect of elevated temperatures. To support this conclusion, further study is currently under way, exploring samples from the second series of the fire tests.
\end{abstract}

KEYwords: Fire test, GLT beam, tensile test, zero strength layer.

\section{INTRODUCTION}

Glued laminated timber (GLT) is a promising renewable material enabling wood to be used for more complex constructions. In this regard, the wood combustibility plays an important role which must be taken into account in every design. When fire occurs in the building, the key task becomes a residual load bearing capacity of wooden parts. Reduced dimensions of the member cross-section can easily be measured in situ after removing the charcoal. Nevertheless, a certain layer is affected by an elevated temperature and is assumed to have zero strength and stiffness. Part 1-2 of Eurocode 5 defines this layer as $d_{0}=7 \mathrm{~mm}$ for the fire duration longer than $20 \mathrm{~min}$ and unprotected surface [1]. Some methods to evaluate this layer are presented in [2] depending on the type of load. The authors provide the zero-strength layer for bending in the range of 9.5 to $20.1 \mathrm{~mm}$. In [3] the thickness of $15 \mathrm{~mm}$ is suggested to be more appropriate for bending. From that, at least $7 \mathrm{~mm}$ below the char-line, i.e. the base of the char layer, the material is expected to have lower load bearing capacity than in the remaining part of the cross-section, which in turn is considered unaffected.

The elevated temperatures are assumed to influence the wood in general. The heat treatment affects various material properties depending on the temperature to which the member is exposed. Several authors presented a rapid decrease of the modulus of elasticity $[4,5]$ and compression strength [6] with temperatures exceeding $220^{\circ} \mathrm{C}$ and $150^{\circ} \mathrm{C}$, respectively. The present article should contribute to this research effort concentrating on Young's modulus of wood material forming the residual cross-section of GLT beams exposed to fire.

The article is divided into six sections. Following the introductory part 1 we describe in Section 2 large scale fire tests. These are supplemented by Pilodyn measurements briefly outlined in Section 3. The main part of this paper is concerned with small scale tensile tests discussed in Section 4 categorized and subsequently evaluated on the grounds of the observed type of failure. The achieved results are further elaborated in Section 5. Section 6 finally reviews the essential findings.

\section{FIRE TEST}

A possible way to examine the effect of elevated temperature on mechanical properties of GLT are quick measurements of Pilodyn indentation and small scale tensile tests. While the former tests can be carried out directly on the construction site on extinguished beams, the tensile tests performed in laboratory require production of samples identified with a specific position relative to the charred surface.

These mechanical tests were preceded by large fire tests described in detail in [7] so only a brief summary is presented here for the sake of clarity. In particular, eight GLT beams, with dimensions of $0.10 \times 0.32 \times 2.38 \mathrm{~m}$ and containing eight layers of lamellae, were exposed to fire for various duration of 20 min (Samples 7 and 8), 30 min (Samples 5 and 6), $40 \mathrm{~min}$ (Samples 3 and 4) and $60 \mathrm{~min}$ (Samples 1 and 2 ) and two types of loading curve. The first loading curve was set according to ČSN EN 1363-1 (Samples $1-4)$ and the second one was set constant at $600^{\circ} \mathrm{C}$ 
with the same initial stage as the previous one (Samples 5 - 8). However, the actual furnace temperature exceeded the set temperatures in most cases.

The horizontal experimental setup simulated ceiling layout and contained two beams in each test. The beams had to carry their self-weight only, no additional load was applied. A poorly laid stone wool insulation on the top of the beams enabled burning from all four sides. During the test, the temperature distribution within the whole cross-section was continuously measured via thermocouples placed in drilled holes in even-numbered beams. However, the fluctuations occurred on temperature curves of samples $1,2,3$, and 4, resulting in unknown temperatures at the end of the measurement. Consequently, these samples were excluded from the tensile tests, except for sample 4, which was accepted for further examination for the sake of comparison. To prevent the temperature fluctuations for the rest of the tested samples, the hole openings had to be covered by a ceramic blanket (Sibral) resulting in three side fire in the middle part of even beams (the beams equipped with thermocouples). The difference between four side and three side fire is evident in Figure 4, where in the case of sample 4 the holes were not covered.

The Pilodyn measurements were carried out along this experimental campaign both prior to and after completing the fire test. With reference to mechanical testing we may invite the interested reader to [7] for the results of three-point bending test performed on burned beams to address the reduction of stiffness and strength of wood exposed to elevated temperature. In this paper, we revisit this issue in the light of the measured Young's moduli only and compare the results provided by Pilodyn and tensile tests.

\section{Pilodyn measurement}

The indentation by Pilodyn 6J device was used to gain estimates of the longitudinal Young's modulus of GLT beams both before and after the fire test. The measurement process is based on driving a spike of $2.5 \mathrm{~mm}$ in diameter into the wood in transverse direction with energy of $6 \mathrm{~J}$. The only output is the penetration depth $d[\mathrm{~mm}]$ with an accuracy of $0.5 \mathrm{~mm}$. The value of Young's modulus $E[\mathrm{GPa}]$ then follows directly from an empirical equation with only one variable $d[\mathrm{~mm}]$ as

$$
E=A-B d
$$

where parameters $A, B$ are determined experimentally. Two such expressions presented in [8] in the form

$$
\begin{gathered}
E_{1}=19.367-0.5641 d, \\
E_{2}=20.15-0.766 d,
\end{gathered}
$$

are examined in this study. The first equation (2) is generally adopted for wood, whereas Eq. (3) was developed for a particular application of GLT beams in bending. Mind that both equations were proposed for wood not exposed to elevated temperatures.

The indentation measurement was performed on all samples before the fire test in the defined grid of $5 \times 8$ points per beam located horizontally $0.2 \mathrm{~m}$ from the left side with $0.5 \mathrm{~m}$ gaps in between and vertically to the middle of each lamella (40 points/beam in total). After the fire test, beams 4, 6, and 8, cleaned from charcoal, were indented in cross pattern (70 points/beam in total).

\subsection{Results}

The mean values of measured depth acquired before and after the fire test together with the resulting Young's moduli computed using Eqs. (2) and (3) are summarized in Table 1. From that, Eq. (2) appears more appropriate if no connection to the type of loading and structural application is given. Apart from that we noticed that some of the depths measured after the test were too big and the resultant moduli provided by both equations became even negative. Therefore, an application of these equations to wood exposed to fire is questionable, as these were originally derived for wood without thermal degradation.

\begin{tabular}{ccccccc}
\hline N. & \multicolumn{2}{c}{$d[\mathrm{~mm}]$} & \multicolumn{2}{c}{$E_{1}[\mathrm{GPa}]$} & \multicolumn{2}{c}{$E_{2}[\mathrm{GPa}]$} \\
& $\mathrm{B}$ & $\mathrm{A}$ & $\mathrm{B}$ & $\mathrm{A}$ & $\mathrm{B}$ & $\mathrm{A}$ \\
\hline 4 & 14.03 & 17.57 & 11.46 & 9.45 & 9.41 & 6.69 \\
5 & 13.85 & - & 11.55 & - & 9.54 & - \\
6 & 13.18 & 19.36 & 11.93 & 8.44 & 10.06 & 5.32 \\
7 & 13.43 & - & 11.79 & - & 9.87 & - \\
8 & 14.16 & 19.01 & 11.38 & 8.64 & 9.30 & 5.59 \\
\hline B - before fire test; A - after fire test \\
\multicolumn{4}{c}{ TABLE 1. Pilodyn 6J indentation measurement. }
\end{tabular}

The mean indentation depth increased after the fire test suggesting reduction of Young's modulus. Note that the resulting depth could be affected by unevenness of the burnt surface. Nevertheless, this reduction was observed when testing different group of samples, where the surface at the location of indents was ground off to eliminate this effect. Besides the identified decrease in values of the longitudinal Young's moduli, no correlation with the fire test duration was identified.

\section{Tensile test}

Small dog bone samples were produced from about $25 \mathrm{~cm}$ long segments cut from five GLT beams sustaining the fire load (Samples 4, 5, 6, 7, 8) and two beams without thermal degradation (control group C). An example of dog bone sample having thickness of about $5 \mathrm{~mm}$ is depicted in Figure 1(a). The samples were extracted across the width of the beam, with the maximum number of 8 samples depending on residual dimensions. Disregarding the outer most lamellae the specimens were produced from two 


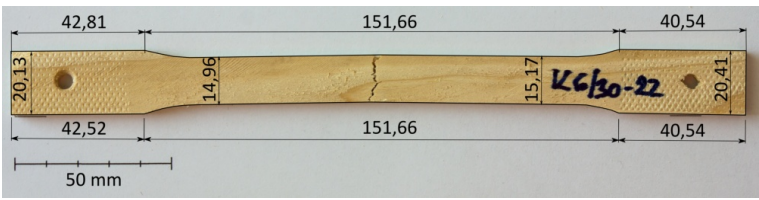

a) Dimensions

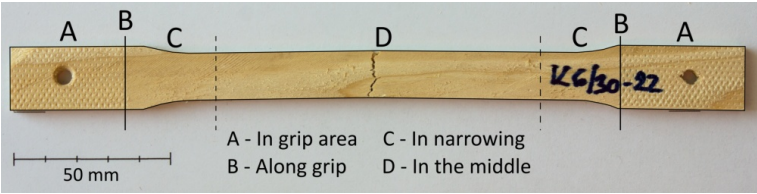

b) Failure crack location

Figure 1. Dog bone sample.

central lamellae (samples denoted as S) and four other lamellae (samples denoted as K) adjacent in pairs to the central ones. The specimens width was aligned with the lamella height. The wood fibers were oriented parallel to the specimen longitudinal axis. Altogether, 406 samples were prepared and tested in the displacement control regime using the MTS Alliance $30 \mathrm{kN}$ electromechanical testing machine equipped with $30 \mathrm{kN}$ load cell. A standard extensometer with length of $100 \mathrm{~mm}$ was used to monitor the strain of the middle part.

The modulus of elasticity is defined as the initial slope of the stress-strain curve. The key output of the tensile test is the load displacement curve. These curves were transformed into stress-strain curves by dividing the load by the initial area measured in the specimen mid section to get the stress and by dividing the extensometer expansion by its initial length $(100 \mathrm{~mm})$ to get the strain. All stress-strain curves were examined separately while eliminating those indicating measurement error, e.g. curves with large fluctuations.

\subsection{DATA EVALUATION}

During careful visual inspection of all damaged samples, different types of failure modes were identified. Comparing the characteristics of individual failures, the specimens were categorized into six groups according to the type of failure crack displayed in Figure 2 in several illustrative examples.

When the clear sample split into parts with irregular edges with splinters, the failure crack was categorized as 'A - along fibers'. If the crack ran directly perpendicular to the fibers, it was denoted as 'B - across fibers'. Natural wood usually contains a certain amount of growth imperfections. The most pronounced are knots, which in many cases acted as a crack initiators depending on its size. The cracks propagated either across the knot ('E') or along the knot ('F'), both with a similar frequency, see Table 4. The group 'D - Discontinuity' covers other discontinuities occurring in wood such as resin pockets, see Figure 2, or change in the fiber direction due to vicinity of the knot. The last type ('C - Delamination')

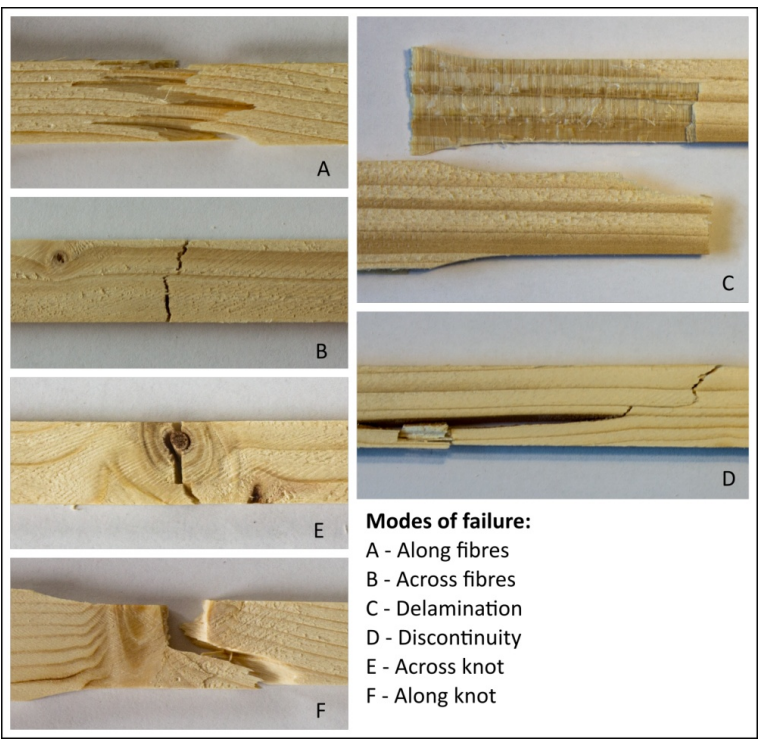

Figure 2. Modes of failure.

occurred only in a few cases, as the sample split into two plates or layers resembling delamination.

Further categorization was based on the location of the crack indicated in Figure 1(b). If the crack extended to more than one location, the decisive factors were the majority of crack extension into a given location or the major impact. Every sample was also rated considering the level of browning ranging from 0 for clear samples to 1 for black. The sample with failure crack running along ('A') or across ('B') the fibers and located in the middle ('D') was considered as the "ideal" one.

\subsection{Results}

The resulting mean and median values of Young's moduli determined from the loading part of the stress-strain curves are presented in Tables 2 - 6 considering the described categorization. The specimens denoted as $\mathrm{C}$ were prepared from beams without thermal degradation, used as a control group. Recall that the $\mathrm{K}$ and $\mathrm{S}$ letters refer to the edge and the middle part of the beam, respectively. The statistical data in Table 5 were evaluated from both all samples (No elimination) and samples considering the type of failure 'A' or 'B' and position 'C' or 'D', thus excluding all samples identified with failure modes 'C', 'D', ' $\mathrm{E}$ ' and ' $\mathrm{F}$ ' and failures occurred in 'A' or along 'B' grip area (With elimination). The effect of discontinuities and other inaccuracies is, therefore, reduced and the resulting moduli are higher. In all cases, the mean value of $(\mathrm{K})$ samples is lower than the one corresponding to $(\mathrm{S})$ samples.

Despite eliminating all non ideal specimens no correlation with the position within the beam width has been found. Considering the same elimination as mentioned previously, the mean value (9.01 GPa) and the median (9.30 GPa) of the browned samples (26) are only slightly lower than the not browned spec- 


\begin{tabular}{|c|c|c|c|}
\hline \multirow[b]{2}{*}{ Browning } & \multicolumn{2}{|c|}{ N. $4,5,6,7,8$} & \multirow{2}{*}{$\begin{array}{l}\mathrm{C} \\
0\end{array}$} \\
\hline & 0 & $>0$ & \\
\hline \multicolumn{4}{|c|}{ No elimination } \\
\hline mean & 9.13 & 8.15 & 7.18 \\
\hline median & 9.06 & 8.43 & 7.02 \\
\hline num & 282 & 43 & 40 \\
\hline \multicolumn{4}{|c|}{ With elimination } \\
\hline mean & 10.18 & 9.01 & 8.53 \\
\hline median & 9.96 & 9.30 & 7.16 \\
\hline num & 120 & 26 & 15 \\
\hline
\end{tabular}

TABLE 2. Young's moduli from tensile test in [GPa] depending on the level of browning.

\begin{tabular}{cccccc}
\hline Pos. & Num. & \multicolumn{4}{c}{$\mathrm{E}[\mathrm{GPa}]$} \\
& & mean & median & $\min$ & $\max$ \\
\hline $\mathrm{A}$ & 20 & 9.18 & 8.05 & 5.70 & 13.89 \\
$\mathrm{~B}$ & 69 & 9.86 & 9.48 & 6.16 & 17.08 \\
$\mathrm{C}$ & 140 & 9.75 & 9.43 & 5.78 & 16.10 \\
$\mathrm{D}$ & 177 & 7.67 & 7.43 & 0.34 & 16.19 \\
\hline
\end{tabular}

TABLE 3. Young's moduli from tensile test according to failure position.

imens (120) with the mean value (10.18 GPa) and the median $(9.96 \mathrm{GPa})$. Without elimination, the mean value $(8.15 \mathrm{GPa})$ and the median $(8.43 \mathrm{GPa})$ of browned samples (43) are still only slightly lower than the not browned specimens (282) with the mean value $(9.13 \mathrm{GPa})$ and the median $(9.06 \mathrm{GPa})^{1}$, see also Table 2. In addition, the control samples which were not exposed to elevated temperatures (denoted as C) experienced the lowest values of Young's moduli compared to the fire test samples, see also Table 5. Mind that due to the process of sample preparation the most burnt parts of the beam were cut off, therefore, the parts most affected by thermal degradation were excluded.

Another examined parameter was the contribution of the position of the failure crack and the failure mode. The position of failure crack according to Figure 1(b) seems not to affect the resulting Young's modulus. The values of Young's modulus listed in Tables 3 and 6 do not differ significantly from each other, even when comparing different positions with the same failure mode. Slightly smaller values of position ' $\mathrm{D}$ ' in Table 3 are caused by a large number of discontinuities (knots and others). Considering the most common failure mode 'A', the mean moduli for all positions are 10.64 GPa (A), 9.74 GPa (B), $9.84 \mathrm{GPa}(\mathrm{C})$, and $10.36 \mathrm{GPa}(\mathrm{D})$, respectively. Unfortunately, the number of data in position ' $\mathrm{A}$ ' is too small to draw any conclusion.

More pronounced are differences among individual modes of failure, recall Figure 2. Again, comparing the values in Tables 4 and 6 , the most significant de-

\footnotetext{
${ }^{1}$ The number of samples is in parentheses.
}

\begin{tabular}{cccccc}
\hline Mode & Num. & \multicolumn{4}{c}{$\mathrm{E}[\mathrm{GPa}]$} \\
& & mean & median & $\min$ & $\max$ \\
\hline $\mathrm{A}$ & 146 & 10.07 & 9.90 & 1.45 & 16.19 \\
$\mathrm{~B}$ & 96 & 9.55 & 9.16 & 4.41 & 17.08 \\
$\mathrm{C}$ & 10 & 9.69 & 8.02 & 6.72 & 14.30 \\
$\mathrm{D}$ & 21 & 8.21 & 7.94 & 4.30 & 13.86 \\
$\mathrm{E}$ & 65 & 5.43 & 5.42 & 0.34 & 15.13 \\
$\mathrm{~F}$ & 68 & 7.79 & 7.89 & 1.53 & 13.88 \\
\hline
\end{tabular}

TABLE 4. Young's moduli from tensile test according to failure mode.

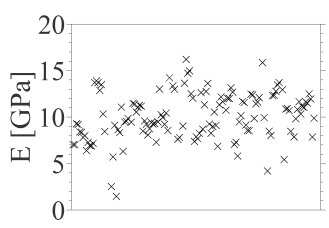

a) A: Along fibers

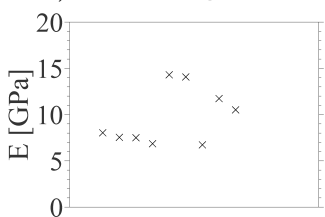

c) C: Delamination

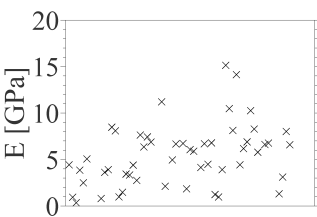

e) E: Across knot

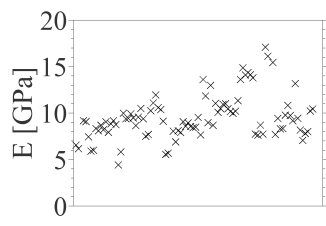

b) B: Across fibers
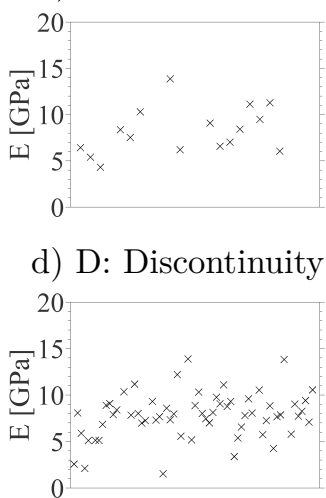

f) F: Along knot d) D: Discontinuity

Figure 3. Young's moduli ( $E[\mathrm{GPa}]$ ) from tensile test for individual failure modes.

crease is in the case of failure across the knot (mode 'E') with the mean value of $5.43 \mathrm{GPa}$. This could be seen in Figure 3, where the measured data of mode 'E' 3(e) fall below those corresponding to mode 'A' 3 (a) or mode 'B' $3(\mathrm{~b})$. Point out that this category (mode 'E') still comprises all types and sizes of knots, which may lead to low as well as high values (see min and max values in Table 4). Differentiating between knots and adopting larger statistical data set would reveal more dependencies. Because Young's moduli in the transverse direction are lower than in the longitudinal, this decrease is reasonable due to change of growth orientation. However, the values still occur in a similar interval (min, $\max$ ) as in other failure modes.

Slightly lower values are observed for the failure along a knot (mode 'F'), where the mean Young's modulus is $7.79 \mathrm{GPa}$. This category comprises the effect of change in fiber orientation along the knot and an imperfect connection between the knot and the surrounding material. Considering the failure along fibers (mode 'A') and across fibers (mode 'B') re- 


\begin{tabular}{|c|c|c|c|c|c|c|c|c|c|c|c|c|c|}
\hline & \multirow{3}{*}{$\begin{array}{l}\text { Time } \\
{[\mathrm{min}]}\end{array}$} & \multicolumn{6}{|c|}{ No elimination } & \multicolumn{6}{|c|}{ With elimination } \\
\hline & & & K & & & $\mathrm{S}$ & & & K & & & $\mathrm{S}$ & \\
\hline & & num & mean & median & num & mean & median & num & mean & median & num & mean & median \\
\hline $\mathrm{C}$ & 0 & 21 & 5.19 & 5.89 & 19 & 9.38 & 9.08 & 10 & 6.91 & 6.98 & 5 & 11.76 & 12.86 \\
\hline 4 & 42 & 28 & 7.18 & 8.14 & 24 & 9.41 & 9.70 & 10 & 7.83 & 8.69 & 14 & 9.34 & 9.70 \\
\hline 5 & 31 & 26 & 7.57 & 7.65 & 29 & 10.55 & 10.58 & 10 & 9.58 & 9.34 & 15 & 11.91 & 12.50 \\
\hline 6 & 31 & 29 & 8.43 & 8.04 & 26 & 8.46 & 8.52 & 17 & 8.91 & 8.25 & 4 & 9.77 & 10.21 \\
\hline 7 & 23 & 37 & 9.87 & 10.20 & 37 & 10.77 & 10.48 & 17 & 10.59 & 11.00 & 15 & 11.96 & 12.76 \\
\hline 8 & 23 & 21 & 8.80 & 9.17 & 25 & 9.31 & 10.32 & 6 & 9.87 & 10.21 & 12 & 10.73 & 11.07 \\
\hline
\end{tabular}

TABLE 5. Young's moduli from tensile tests in [GPa] with or without elimination.

\begin{tabular}{ccccccc}
\hline Pos. & Mod. & N. & \multicolumn{5}{c}{ E [GPa] } \\
& & & mean & median & $\min$ & $\max$ \\
\hline A & A & 4 & 10.64 & 11.49 & 5.70 & 13.89 \\
A & B & 3 & 10.02 & 8.20 & 8.09 & 13.79 \\
A & C & 1 & 11.73 & 11.73 & 11.73 & 11.73 \\
A & D & 2 & - & - & - & - \\
A & E & 1 & - & - & - & - \\
A & F & 9 & 7.82 & 7.75 & 7.00 & 9.31 \\
B & A & 11 & 9.74 & 9.84 & 7.29 & 12.16 \\
B & B & 50 & 9.87 & 9.42 & 6.16 & 17.08 \\
B & C & 0 & - & - & - & - \\
B & D & 0 & - & - & - & - \\
B & E & 3 & 10.84 & 10.84 & 10.48 & 11.21 \\
B & F & 5 & 9.48 & 9.60 & 9.08 & 9.76 \\
C & A & 72 & 9.84 & 9.47 & 5.80 & 15.85 \\
C & B & 26 & 10.25 & 10.07 & 6.54 & 16.10 \\
C & C & 4 & 8.22 & 7.76 & 6.85 & 10.50 \\
C & D & 6 & 8.82 & 9.48 & 6.03 & 11.27 \\
C & E & 14 & 8.69 & 8.20 & 5.78 & 15.13 \\
C & F & 18 & 9.81 & 8.86 & 7.34 & 13.88 \\
D & A & 59 & 10.36 & 11.12 & 1.45 & 16.19 \\
D & B & 17 & 7.52 & 7.92 & 4.41 & 9.73 \\
D & C & 5 & 10.65 & 10.80 & 6.72 & 14.30 \\
D & D & 13 & 7.93 & 7.52 & 4.30 & 13.86 \\
D & E & 47 & 4.55 & 4.40 & 0.34 & 14.13 \\
D & F & 36 & 6.77 & 7.08 & 1.53 & 10.53 \\
\hline & & & & & &
\end{tabular}

TABLE 6. Young's moduli from tensile test for combining positions of failure cracks and corresponding failure modes.

sulted in similar mean values, namely $10.07 \mathrm{GPa}$ and 9.55 GPa. The remaining modes ('C' and 'D') are represented by small data sets, so further conclusion could not be drawn.

\section{Discussion}

The results obtained from small-scale tensile tests suggest that the wood variability and the effect of growth discontinuities are probably more significant than the effect of elevated temperature. This is evident when comparing the values of Young's modulus obtained from all samples, recall Table 2, and those pertinent to samples free of defects summarized in Tables 4 and 6 also identifying the effect of vari- ous failure modes. However, we should still keep in mind that producing the specimens requires rubbing down the surface layer. This is because the outline of the beam's cross-section is rather wavy, see Figure 4, and the specimen surface needs to be flat. Thus the parts of wood, most affected by elevated temperatures, were essentially removed. Nevertheless, a certain amount of browning was observed on 43 specimens (Table 2, which indicates temperatures of at least $221^{\circ} \mathrm{C}$ (for a light brown) [5]. Only four samples evinced dark brown color evaluated as 0.8 (level of browning). Not a single black sample with browning level 1 was found.

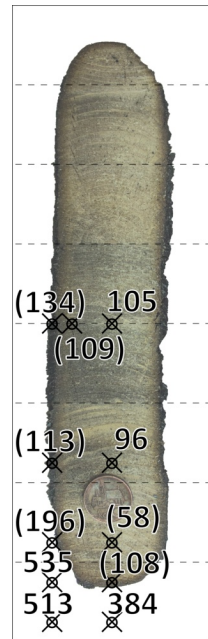

a) Sample 4

(42.15 $\mathrm{min})$

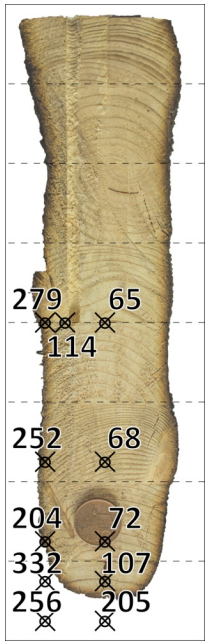

b) Sample 6 (31.40 min)

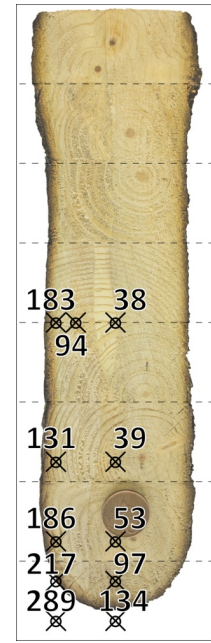

c) Sample 8 $(22.90 \mathrm{~min})$
Figure 4. Temperature distribution $\left[{ }^{\circ} \mathrm{C}\right]$ within cross-section at the end of the fire test (the last measured value before fluctuations occurred is presented in pictures in parentheses).

Figure 4 shows residual cross-sections in the midspan of the beams with temperatures measured by thermocouples at the end of the fire test. The numbers in parentheses denote the last measured values before fluctuations occurred on temperature curves. The temperatures close to the cross-section outline are relatively low, which also suggests a rather smaller thickness of the zero-strength layer, reminding a rapid decrease of the modulus of elasticity above $220^{\circ} \mathrm{C}$ 
$[4,5]$. However, the values on the edges of the crosssection are below a widely accepted temperatures of $300^{\circ} \mathrm{C}$ [1] or $288^{\circ} \mathrm{C}\left(550^{\circ} \mathrm{F}\right)[9,10]$, which defines the base of the char layer (i.e. pyrolysis temperature). This could mean either position error within the picture or that the charring starts at lower temperatures, where e.g. Lange et al. [3] defined the char front already at $270^{\circ} \mathrm{C}$.

Nonetheless, the results of the Pilodyn indentation in Table 1 shows a certain decrease of the longitudinal moduli. Even if the presented equations (2) and (3) were not applicable to wood loaded by fire, the indentation depths after the fire test are still higher than that obtained before the test. Therefore, an assumption of the softening of surface layers of charred beams is reasonable.

\section{Conclunsions}

The tensile test was performed on small dog bone samples, produced from five beams sustaining the fire load and two beams without thermal degradation, to obtain the longitudinal Young's moduli. The samples were extracted across the beam width from two locations - $(\mathrm{K})$ and $(\mathrm{S})$ samples. The specimens were also categorized into groups according to a defined failure mode, Figure 2, and the failure position, Figure $1(\mathrm{~b})$, and they were also rated considering the level of browning (0-without browning, 1-black).

The resulting Young's moduli are stated in Table 5 considering all samples as well samples upon elimination of those with the failure crack located in or along the knot or other discontinuity and those occurring in or along the grip area.

Despite elimination, no correlation with position within the beam width has been found. The browned samples showed only slightly lower values than the not browned specimens, recall Table 2. In addition, the control samples not exposed to elevated temperatures evinced the lowest values of Young's moduli.

On the contrary, larger decrease of the moduli was observed by Pilodyn 6J indentation. The differences between values measured before and after the fire test, see Table 1, lead to an assumption that at least the properties of the surface layers are reduced. But keep in mind that Eqs. (2) and (3) were originally derived for members not exposed to elevated temperature and their applicability could be considered questionable. Nevertheless, the increased indentation depth still shows some level of softening of the surface.

The largest reduction of the measured Young's moduli was observed for failure modes where the failure crack propagated across the knot (mode 'E'), see Tables 4 and 6, and Figure 3. Therefore, the presence of knots affects the resulting material properties more than the elevated temperatures. Less pronounced effect was also observed for modes 'F' (along knot) and 'D' (discontinuity). On the other hand, no correla- tion with the position within the dog bone sample was found as evident from Tables 3 and 6 .

The results obtained from the small-scale tensile tests suggest that the wood variability and the effect of growth discontinuities are probably more significant than the effect of elevated temperature. To support this conclusion, further study is currently under way exploring samples from the second series of the fire tests.

\section{LIST OF SYMBOLS \\ $E$ Young's modulus [GPa] \\ $d \quad$ Pilodyn 6J indentation depth [mm] \\ $K$ Samples from edges (cross-section height point of view) \\ $S$ Samples from middle (cross-section height point of view) \\ $C$ Control samples \\ $A-D$ Failure position (Figure 1) \\ $A-F$ Modes of failure (Figure 2)}

\section{ACKNOWLEDGEMENTS}

The financial support provided by the Czech Technical University in Prague within SGS project with the application registered under the No. SGS20/155/OHK1/3T/11 and by the GAČR grant No. $18-05791 \mathrm{~S}$ is gratefully acknowledged.

\section{REFERENCES}

[1] European Committee for Standardization. Eurocode 5: Design of timber structures - part 1-2: General structural fire design, 2004.

[2] J. Schmid, A. Just, M. Klippel, M. Fragiacomo. The reduced cross-section method for evaluation of the fire resistance of timber members: Discussion and determination of the zero-strength layer. Fire technology 51(6):1285-1309, 2015. DOI:10.1007/s10694-014-0421-6.

[3] D. Lange, L. Boström, J. Schmid, J. Albrektsson. The influence of parametric fire scenarios on structural timber performance and reliability. Tech. rep., SP Technical Research Institute of Sweden, 2014.

[4] B. Esteves, H. Pereira. Wood modification by heat treatment: A review. BioResources 4(1):370-404, 2008.

[5] D. Kačíková, F. Kačík, I. Čabalová, J. Ďurkovič. Effects of thermal treatment on chemical, mechanical and colour traits in norway spruce wood. Bioresource Technology 144:669-674, 2013. DOI:10.1016/j.biortech.2013.06.110.

[6] S. Yildiz, E. D. Gezer, U. C. Yildiz. Mechanical and chemical behavior of spruce wood modified by heat. Building and environment 41(12):1762-1766, 2006. DOI:10.1016/j.buildenv.2005.07.017.

[7] L. Kucíková, T. Janda, M. Šejnoha, J. Sýkora. Experimental investigation of fire resistance of GLT beams. International Journal of Computational Methods and Experimental Measurements 8(2):99-110, 2020. DOI:10.2495/CMEM-V8-N2-99-110. 
[8] M. Šejnoha, T. Janda, L. Melzerová, et al. Modeling glulams in linear range with parameters updated using Bayesian inference. Engineering Structures 138:293307, 2017. DOI:10.1016/j.engstruct.2017.02.021.

[9] American Wood Council. Calculating the fire resistance of wood members and assemblies, technical report no. 10, 2020.

[10] R. H. White, E. V. Nordheim. Charring rate of wood for astm e 119 exposure. Fire technology 28(1):5-30, 1992. DOI:10.1007/BF01858049. 